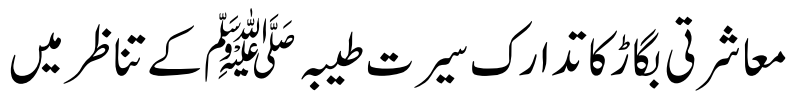

\title{
Remedies of Social Decadence in Context of the Life of Prophet Muhammad (Peace be upon him)
}

Rabia* $^{*}$

\begin{abstract}
In this article, putrefaction of society has been discussed along with the counterstrategies adopted by the Prophet (Peace be upon him). Since social vices have been the vestigial part of the Arab society, the Prophet (Peace be upon him) took up the cudgels and bestirred to eradicate moral decay, existent among the Arabs from the days of yore. Analogous to the situation, in the contemporary world, the similar social vices are being erected on the pretext of 'modernization', which has become the cause of demoralization for many. For this, in the current article, social maladies and moral turpitude like fib, backbiting, adultery, grudge, rancor etc. have been delineated. After being involved in elusive bustling, an individual blemishes his or her life in this world and hereafter, affecting Peace and Stability in the society. The only way out that one can adopt to escape herself/himself from this, is the way that has been unfolded by the Prophet (Peace be upon him). So, by acting upon the Prophet's (Peace be upon him) instructions we can curb these social vices and moral turpitude in our society.
\end{abstract}

Keywords: putrefaction, expediencies, peace, stability, moral.

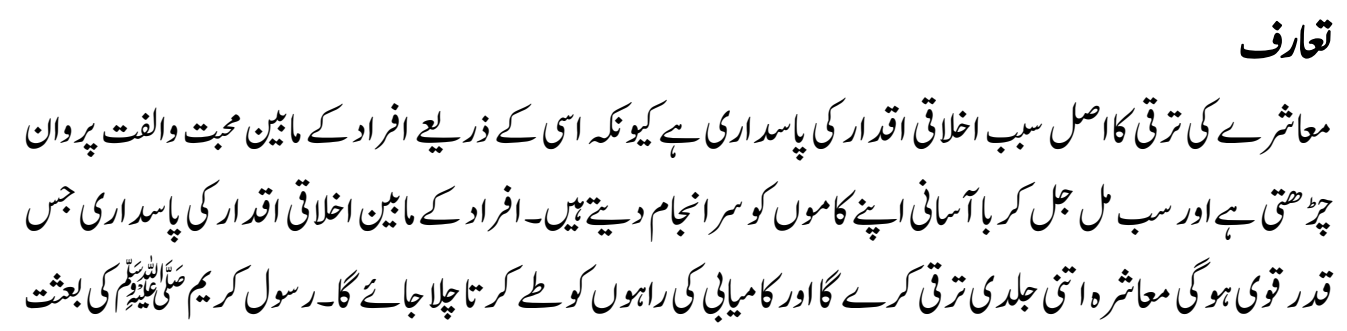

\footnotetext{
* Ms. Rabia Visiting Lecturer, University of Karachi. Karachi rabiaimtiaz94@yahoo.com
} 


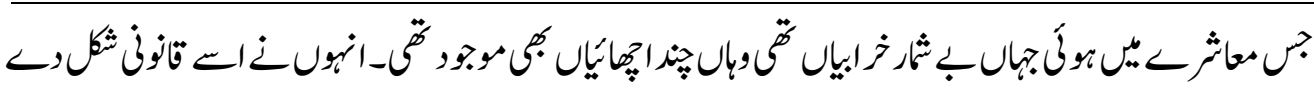

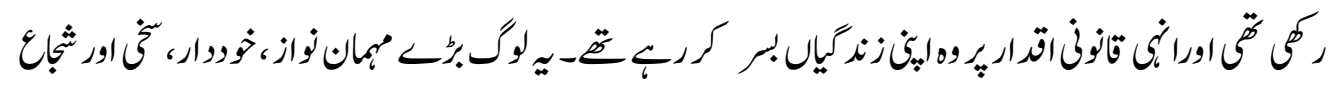

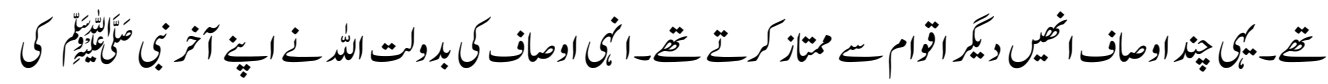

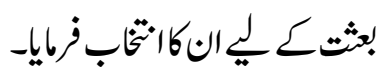

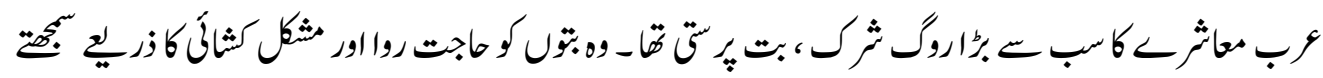

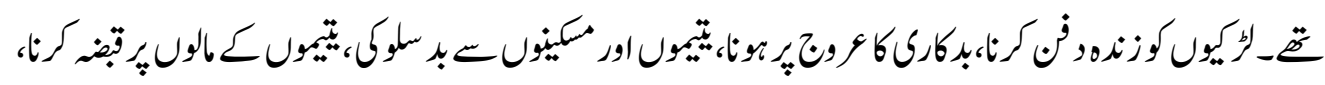

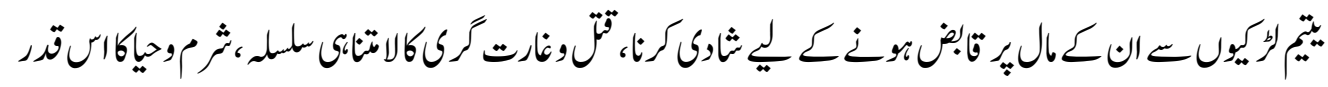

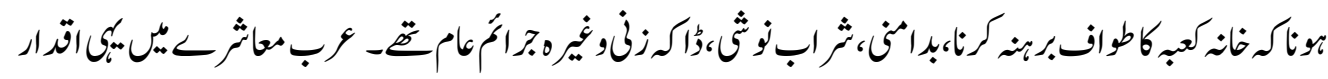

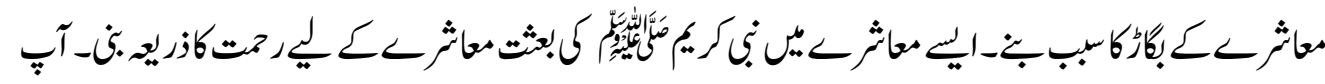

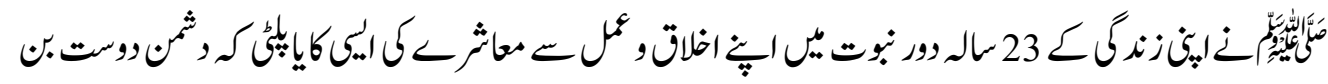

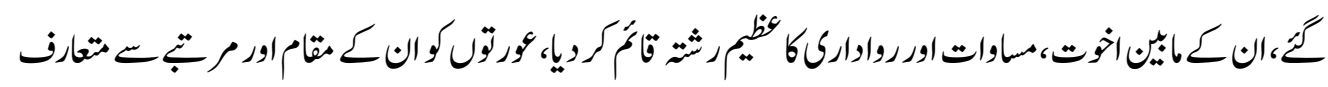

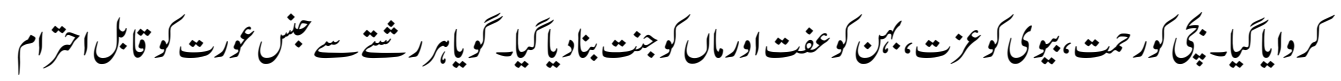

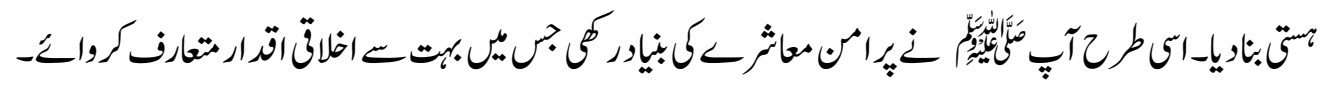

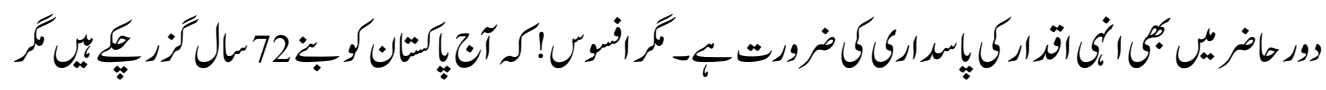

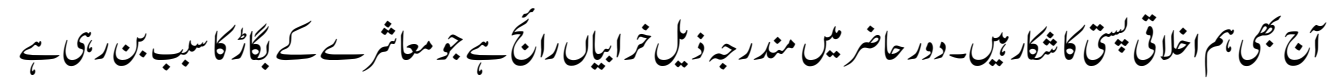

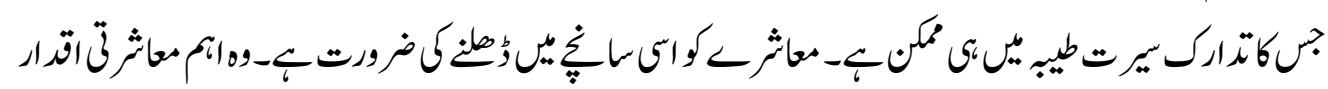

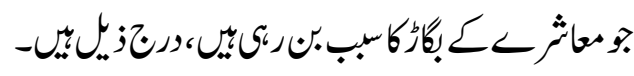

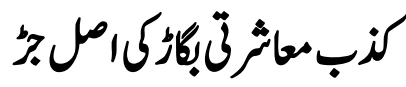

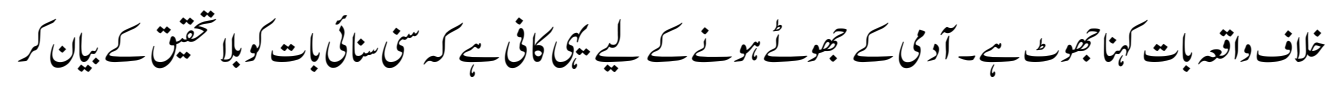

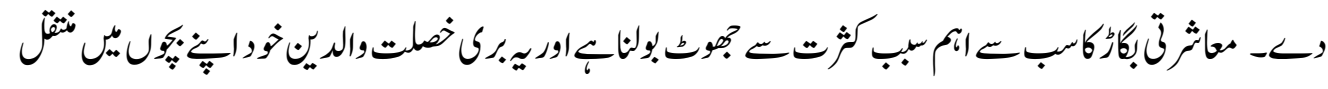




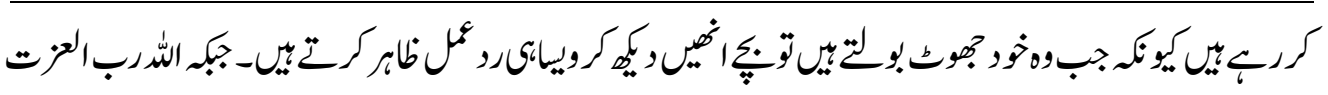

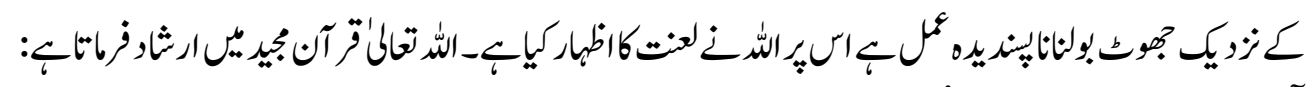

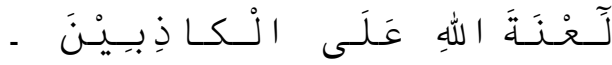

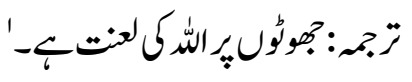

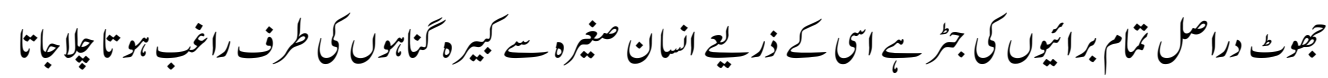

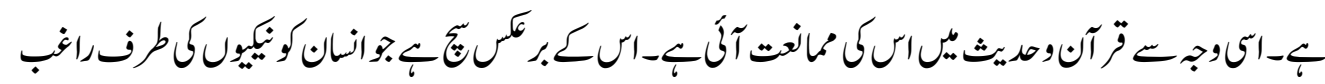

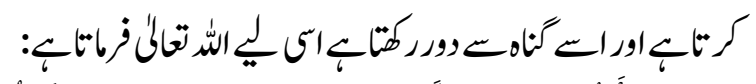

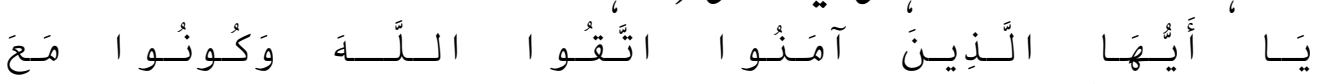

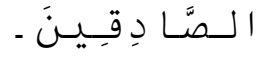

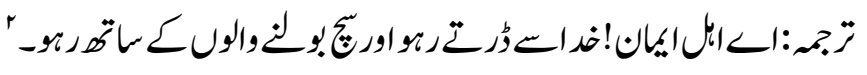

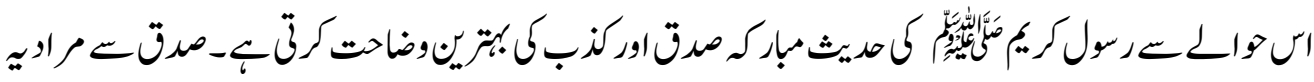

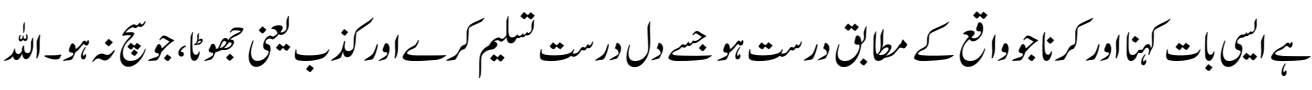

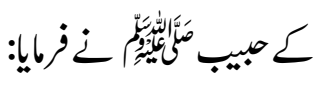

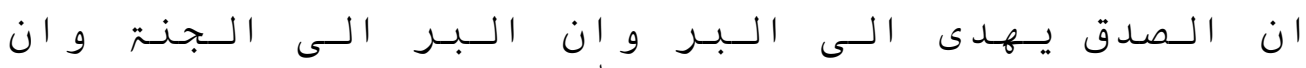

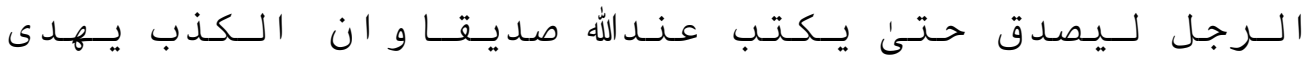

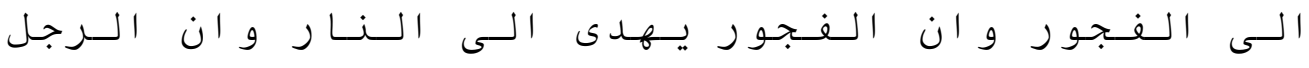

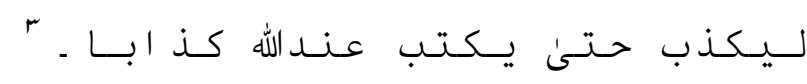

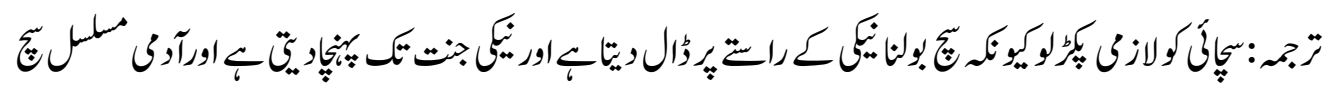

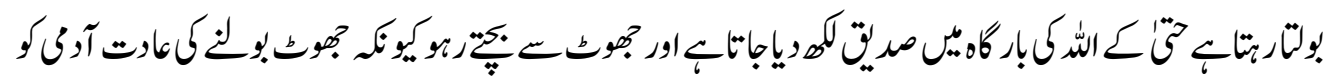

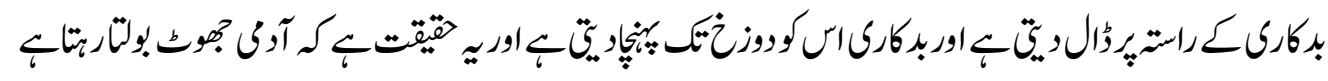

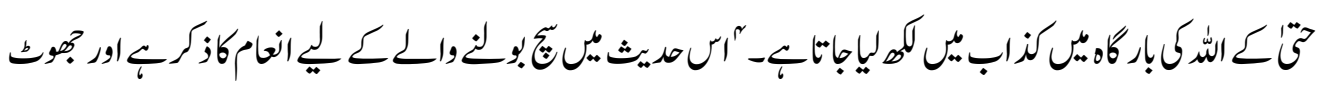

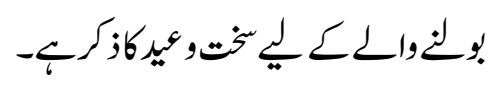




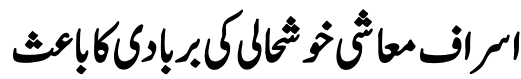

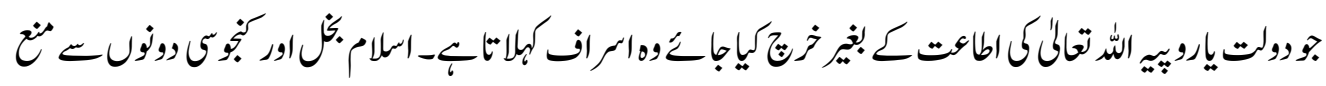

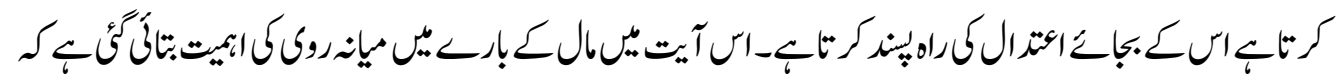

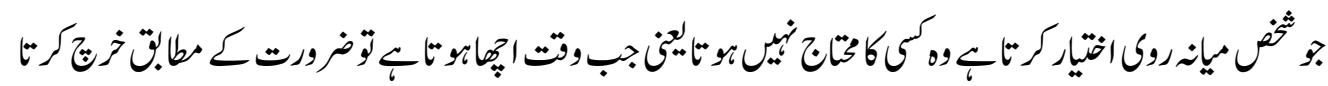

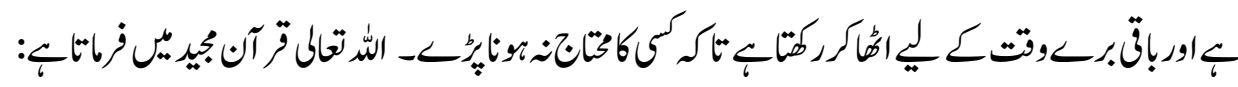

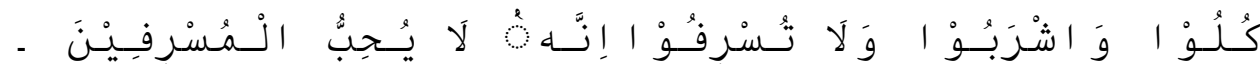

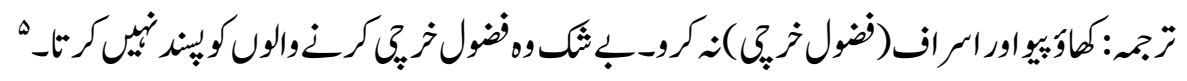

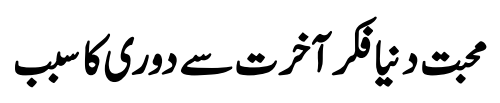

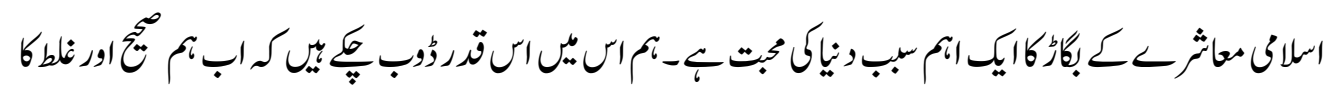

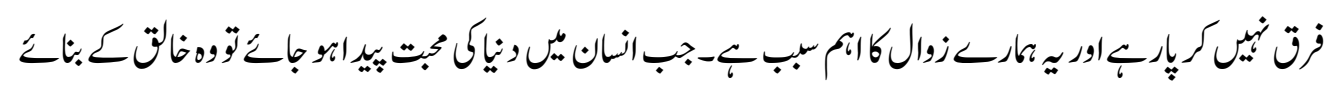

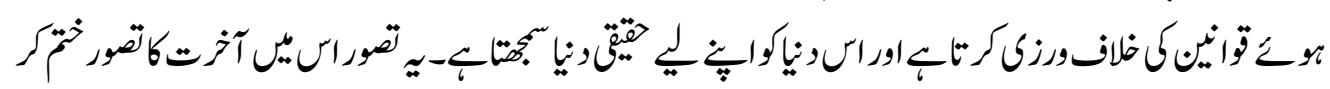

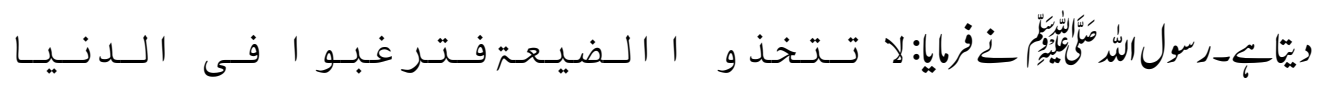

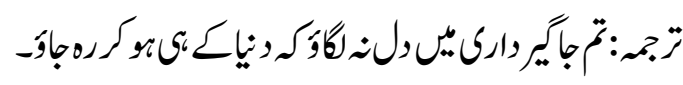

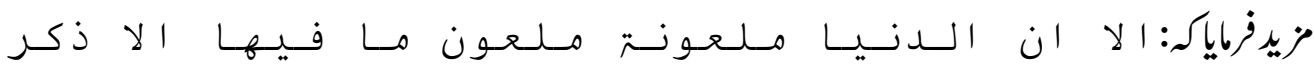

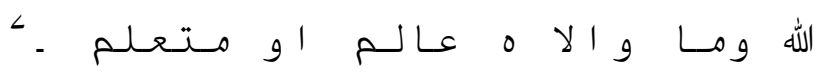

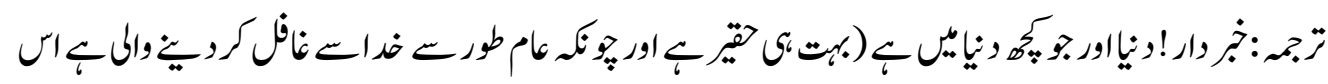

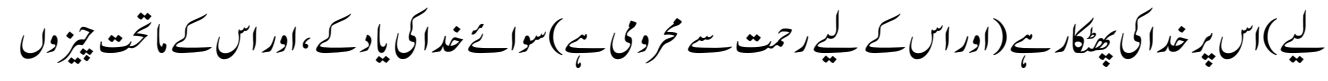

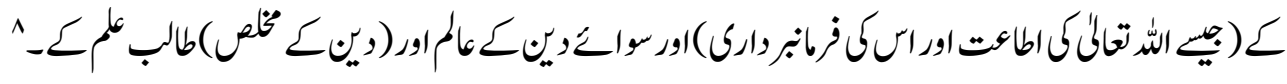




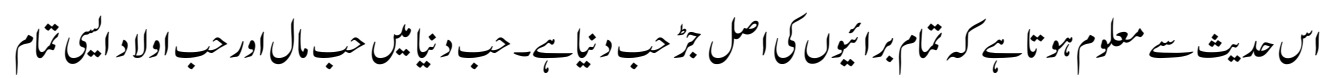

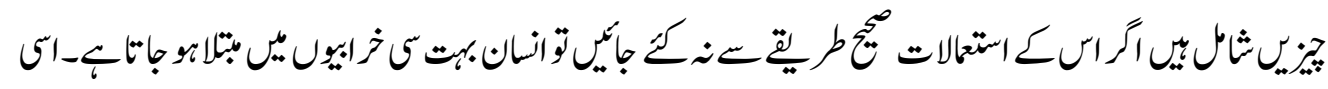

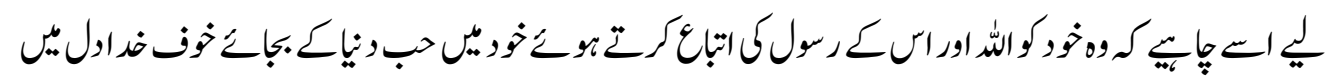

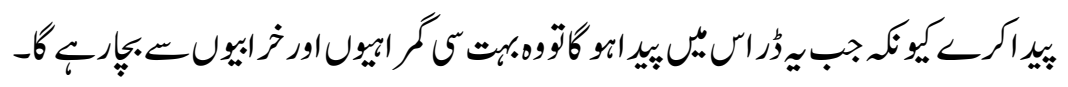

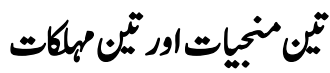

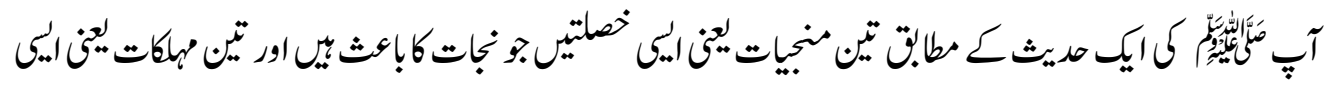

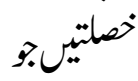

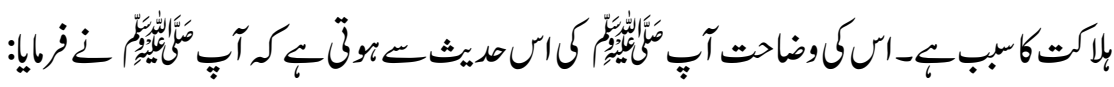

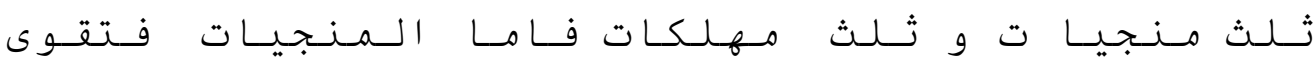

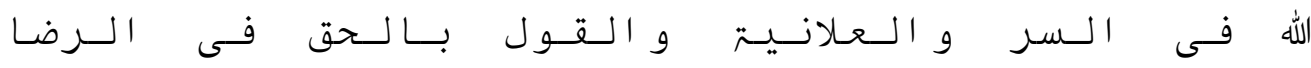

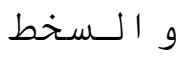

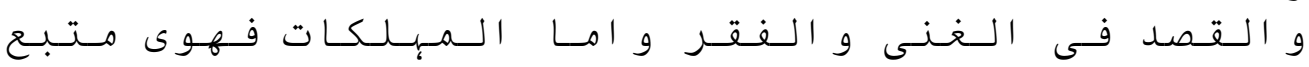

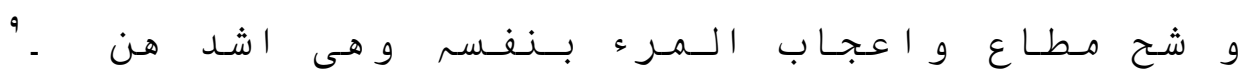

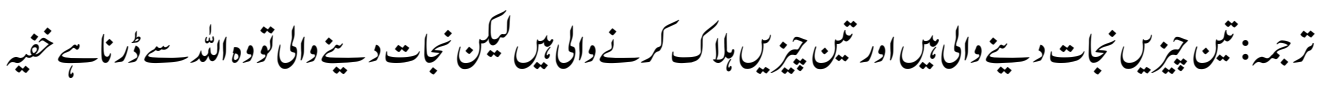

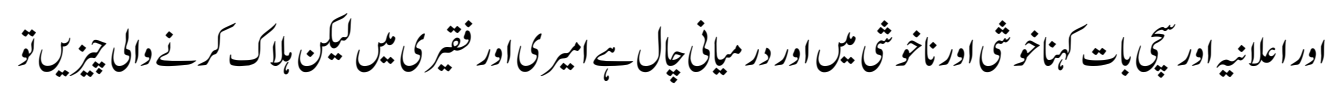

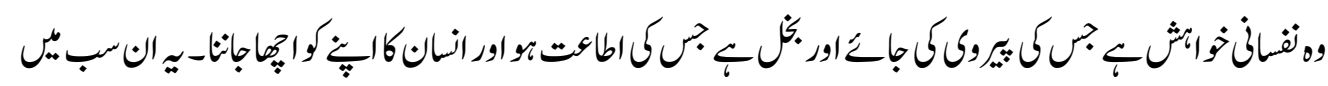
1.

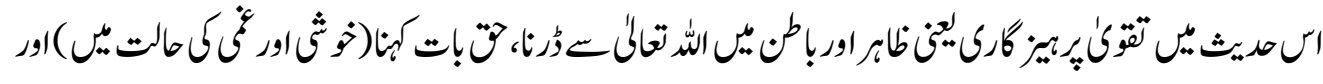

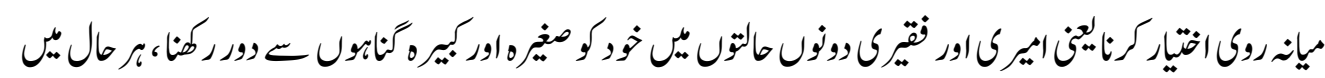

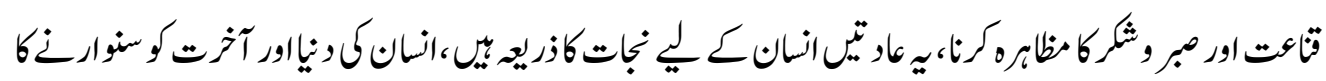

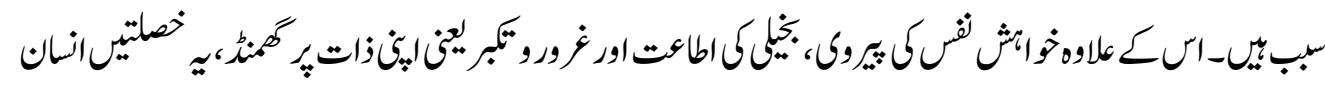

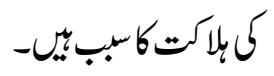




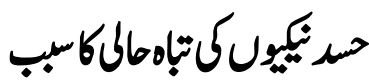

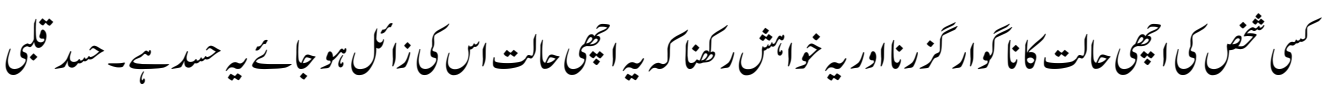

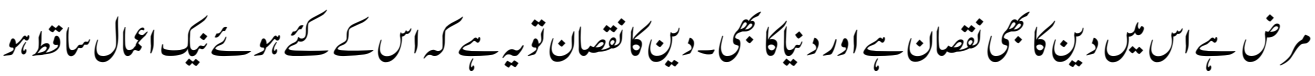

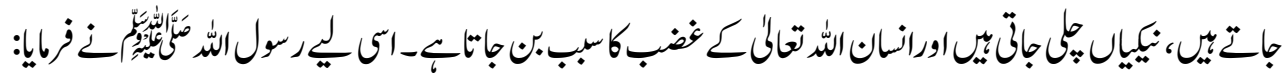

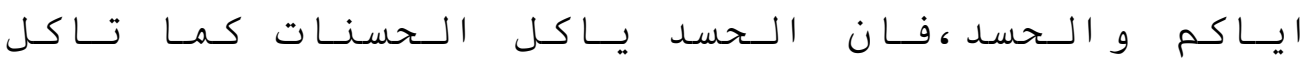

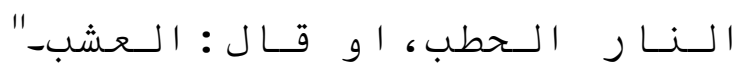

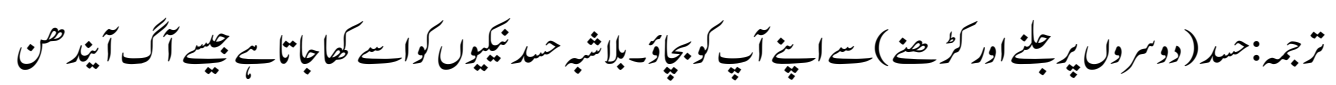

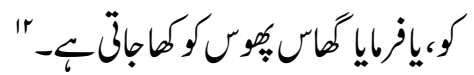

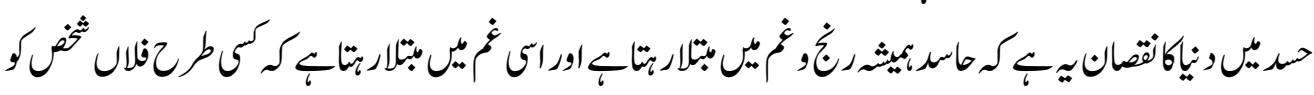

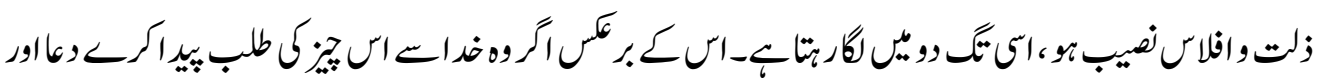

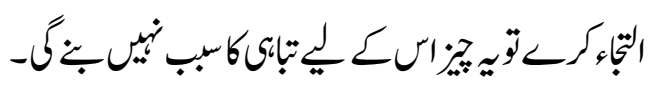

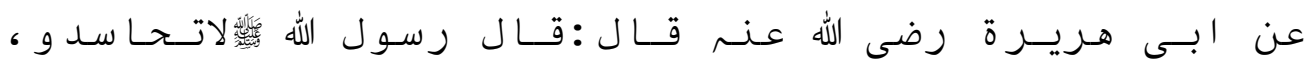

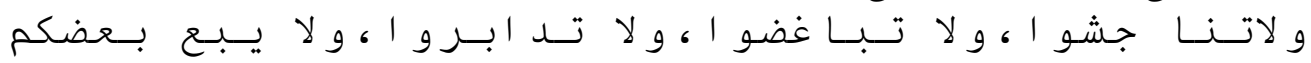

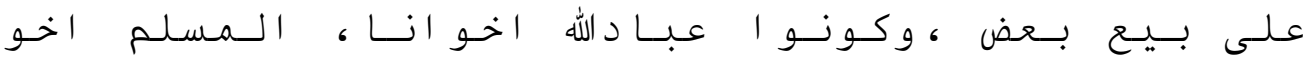

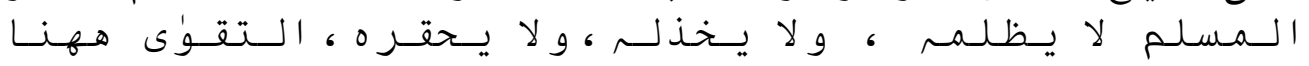

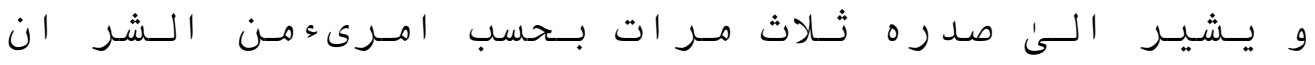

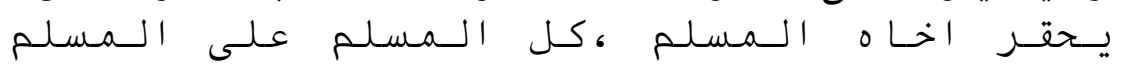

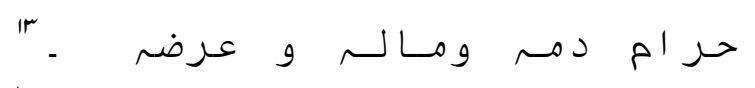

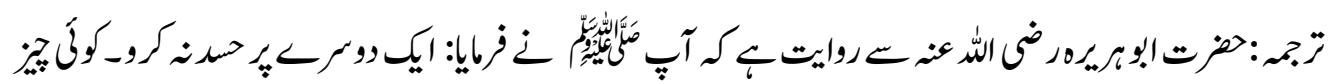

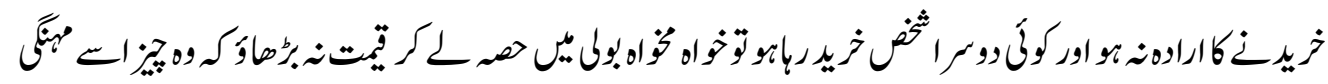

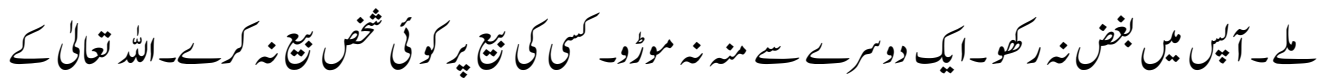

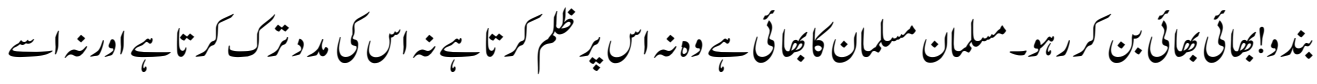




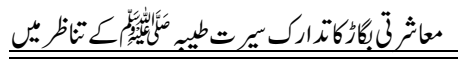

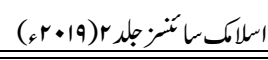

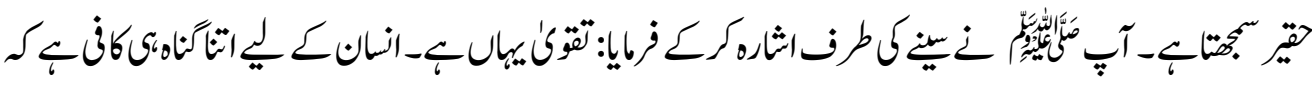

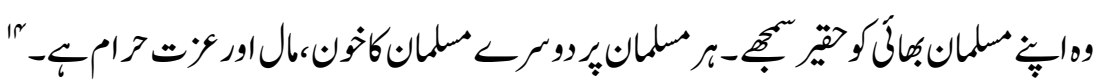

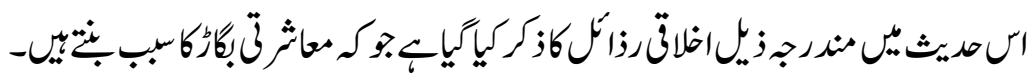
أ. آ. حس كرنا-

$$
\begin{aligned}
& \text { ب. بالاضروت يقيت كورطاطنا- }
\end{aligned}
$$

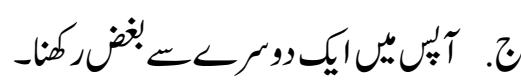

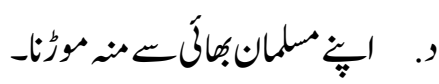

$$
\begin{aligned}
& \text { ه. تنجبراندروثاضتياركرنا }
\end{aligned}
$$

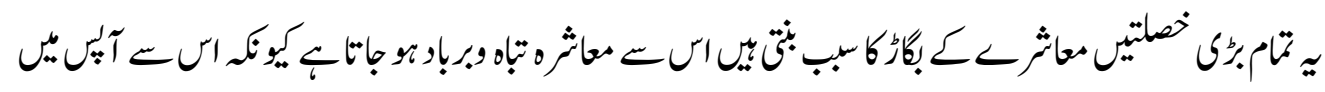

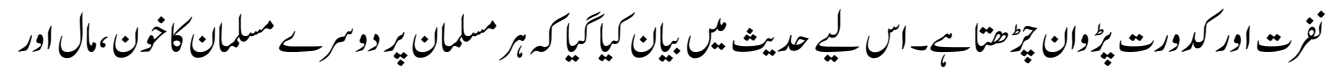

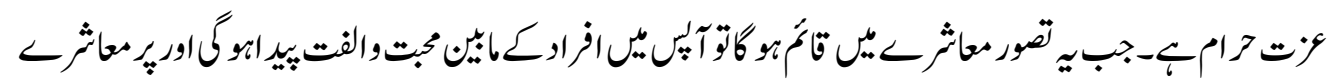

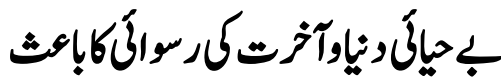

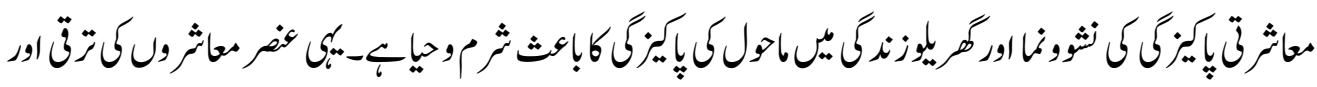

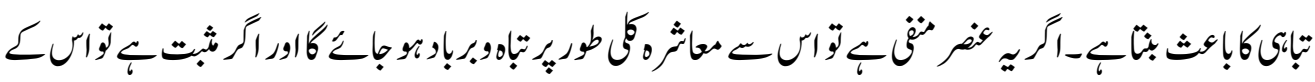

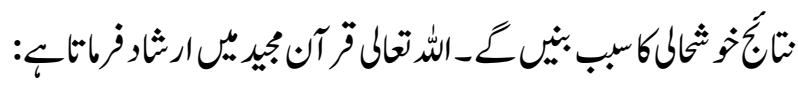

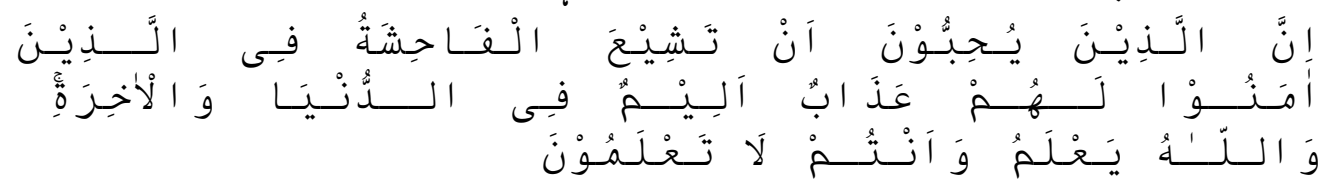

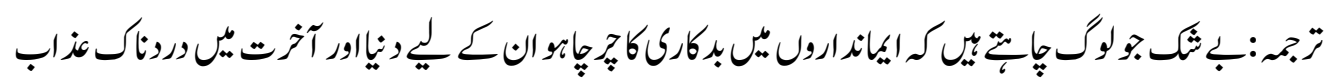

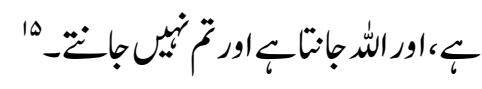




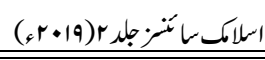

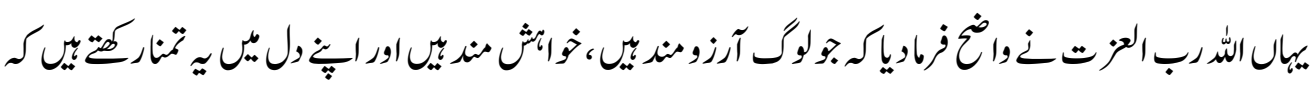

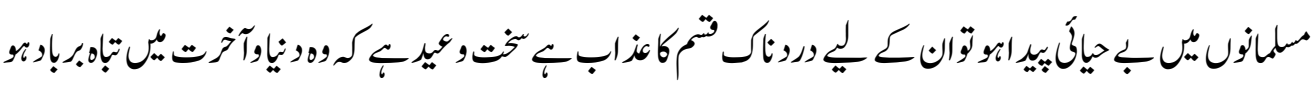

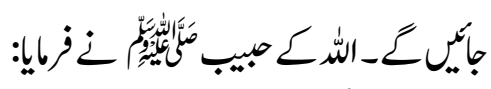

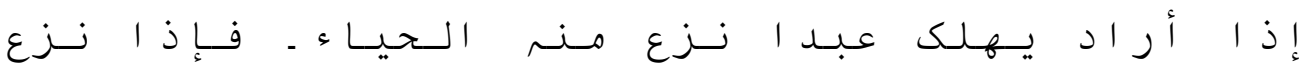

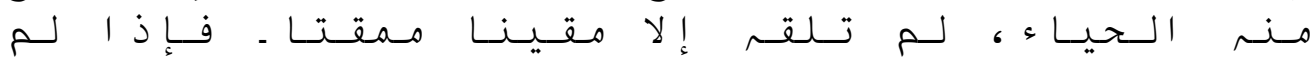

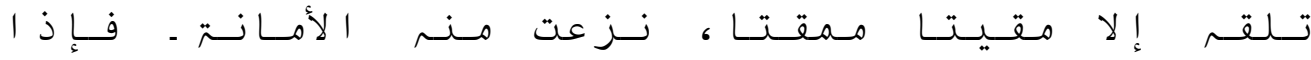

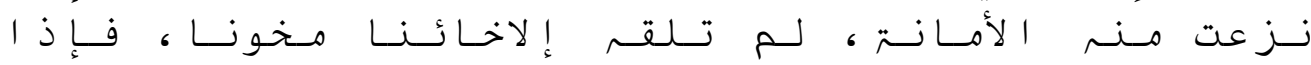

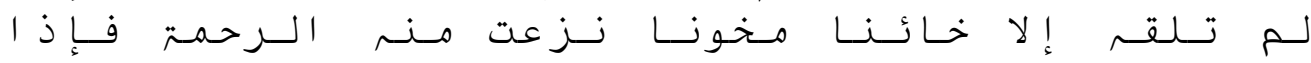

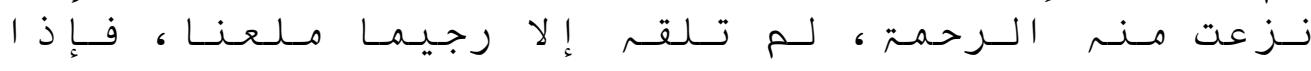

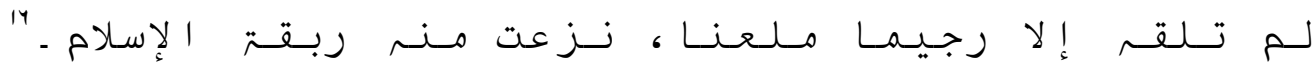

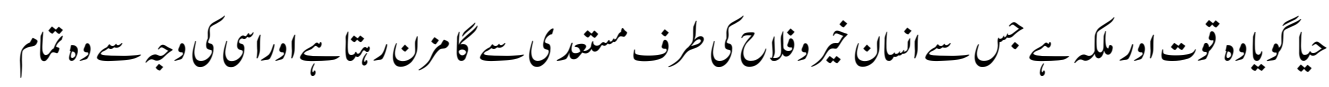

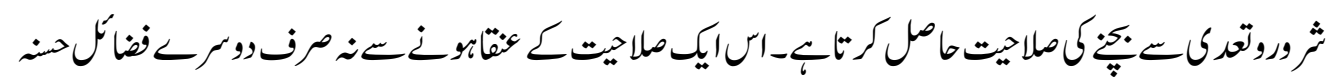

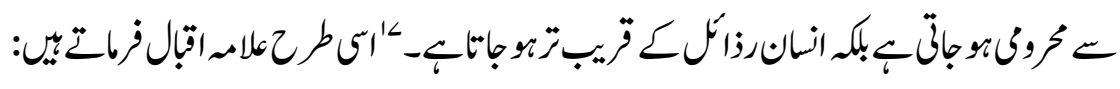

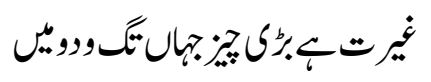

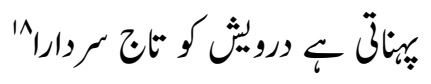

\section{ناشكرى نتمتونع زوالكاباوث}

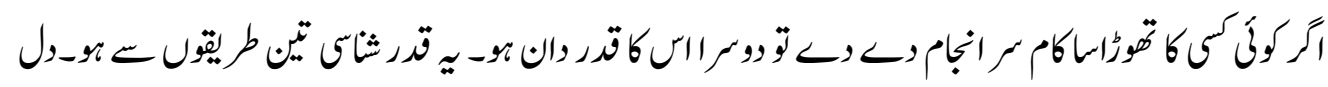

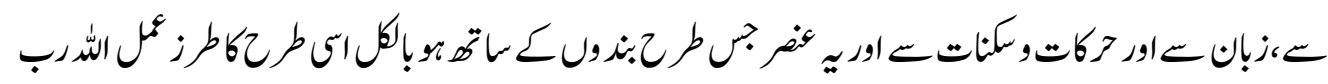

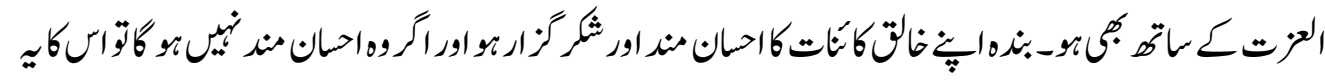

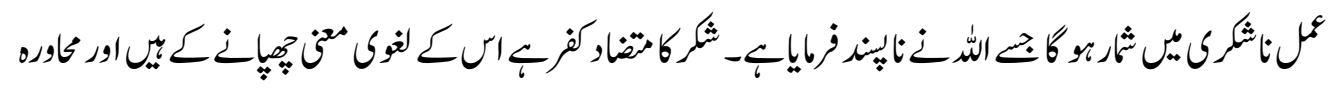

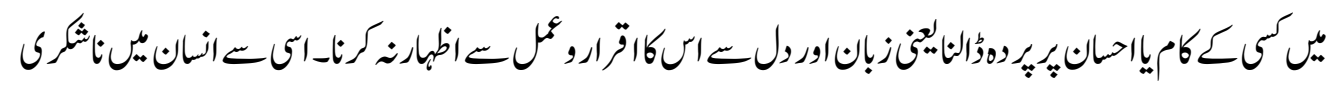

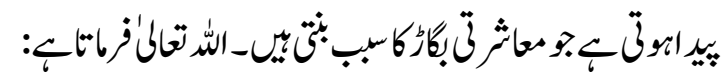

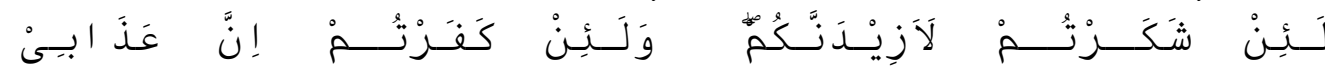

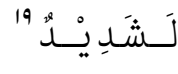




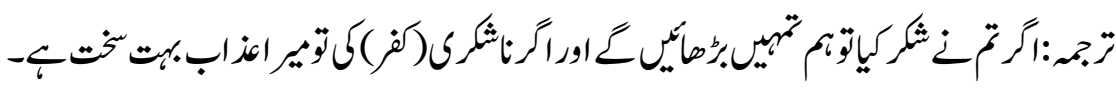

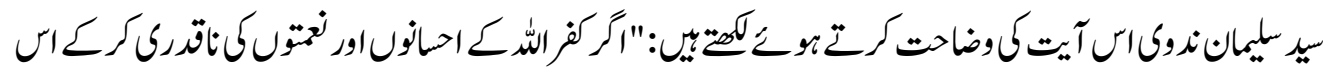

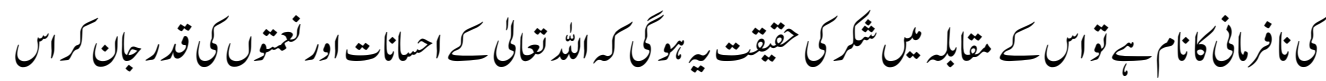

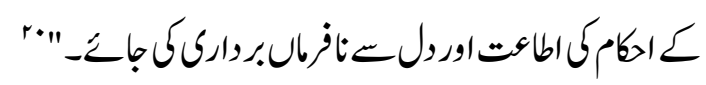

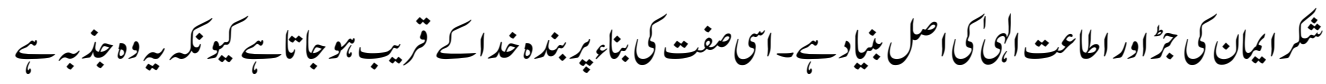

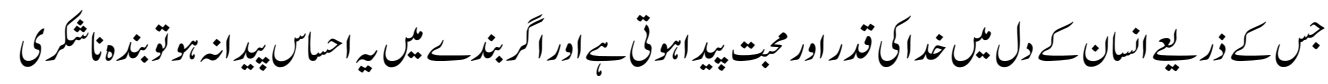

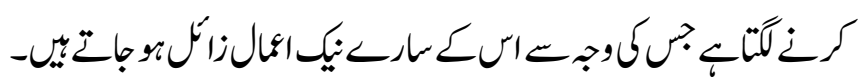

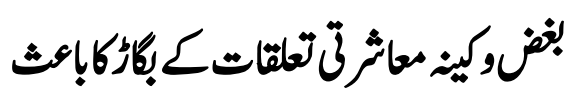

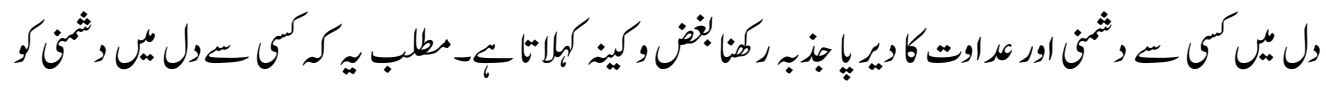

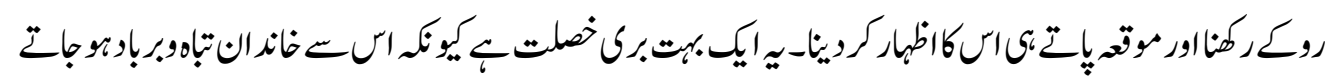

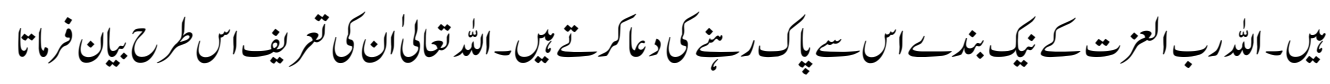

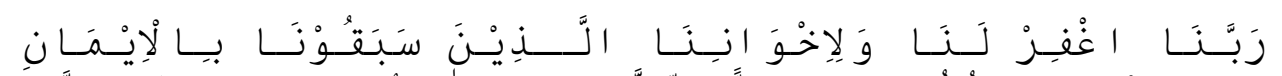

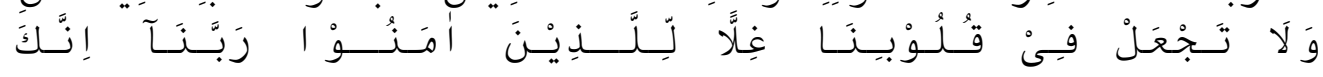

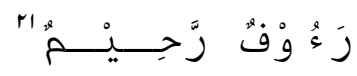

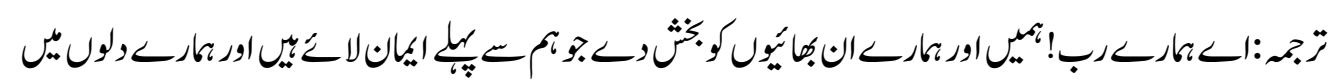

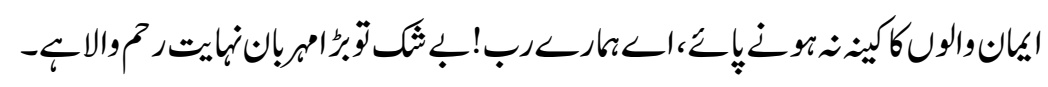

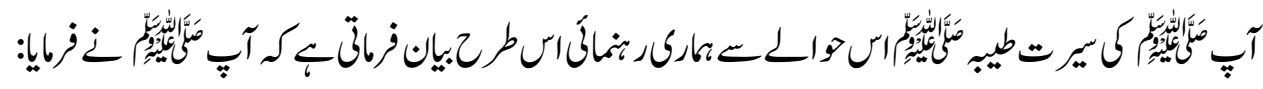

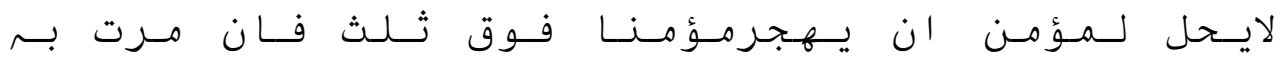

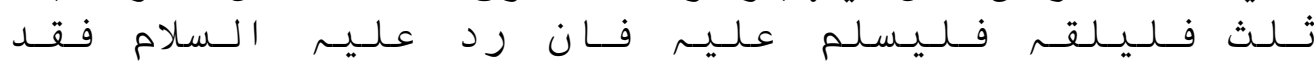




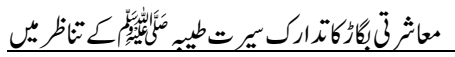

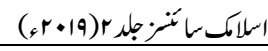

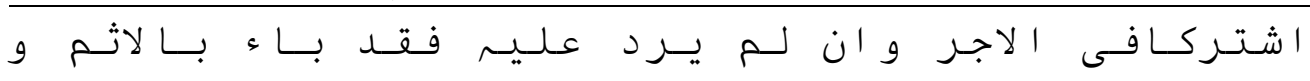

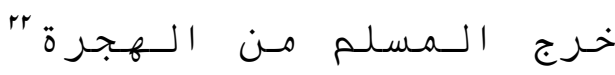

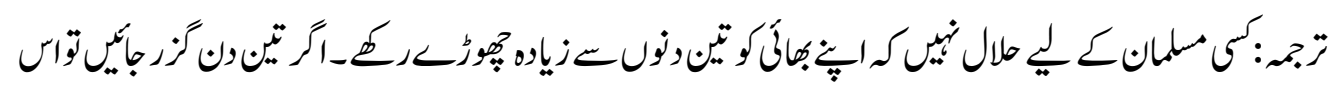

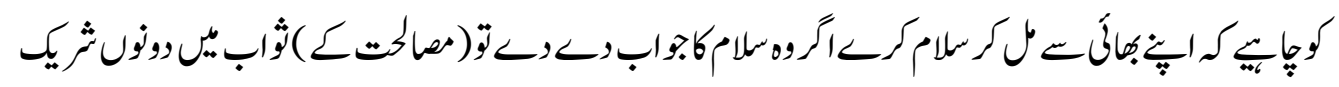

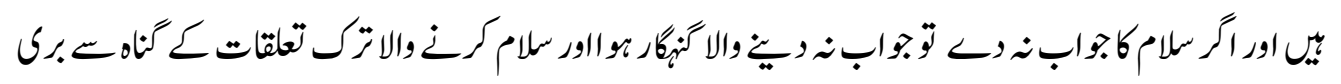
r

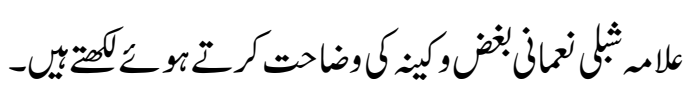

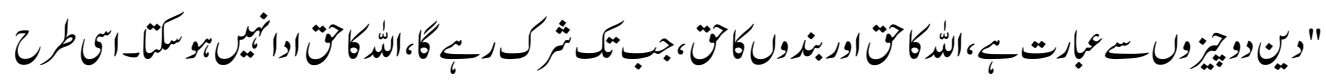

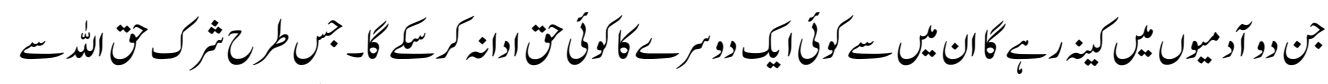

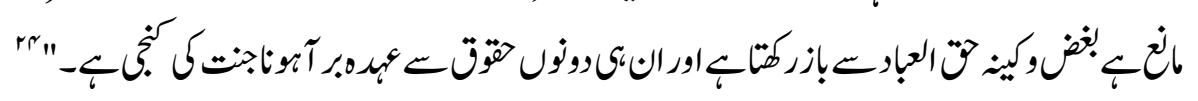

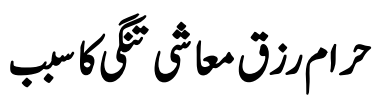

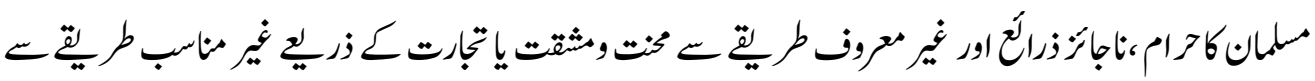

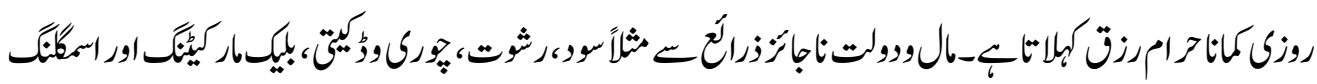

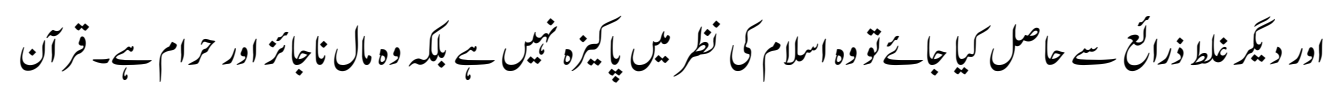

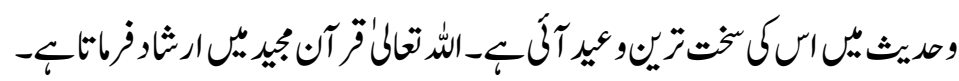

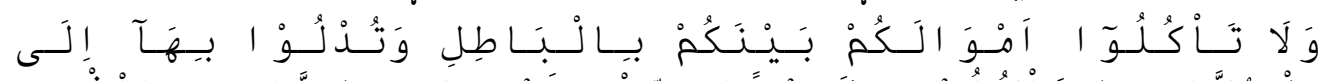

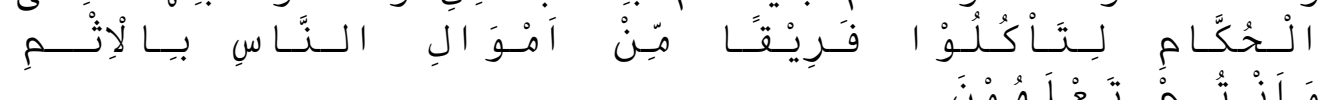

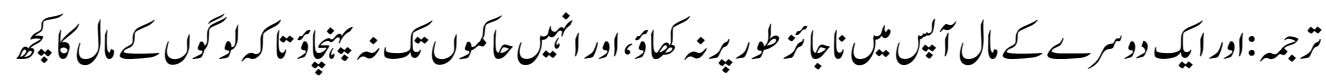

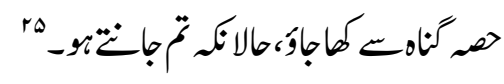




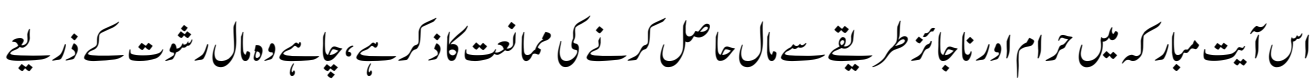

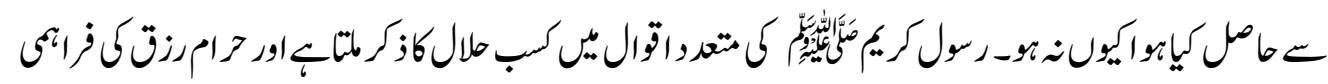

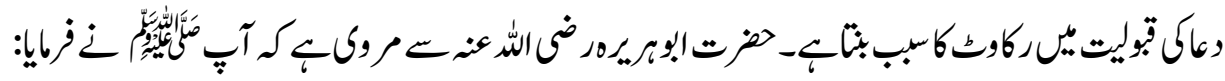

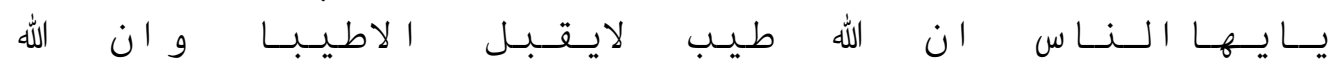

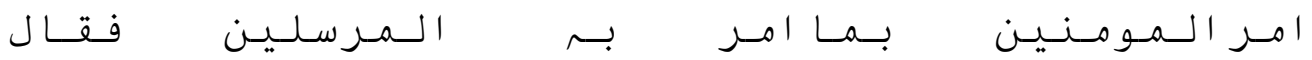

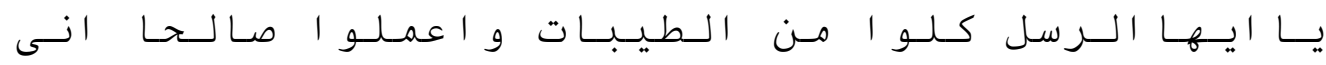

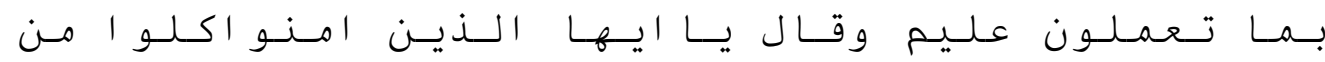

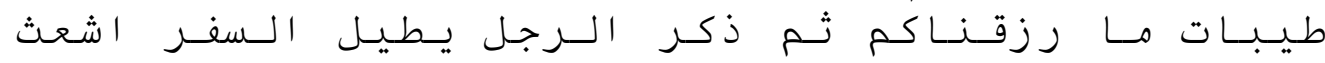

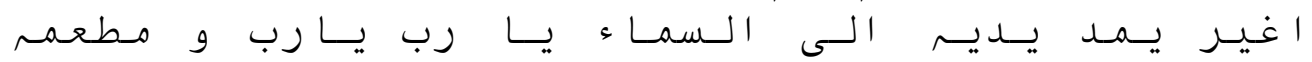

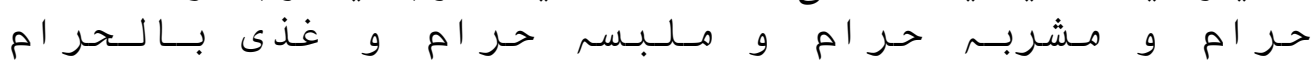

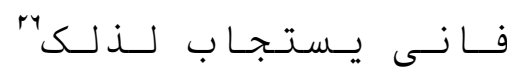

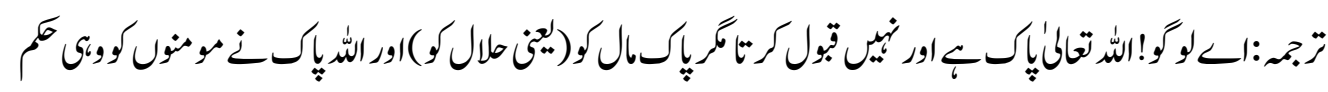

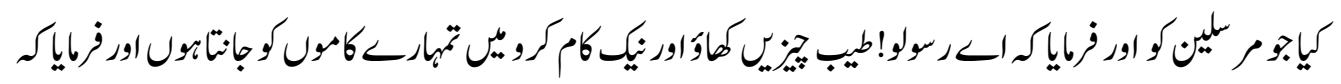

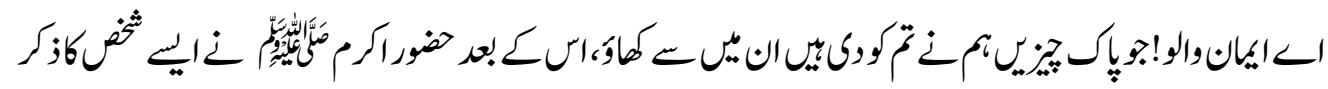

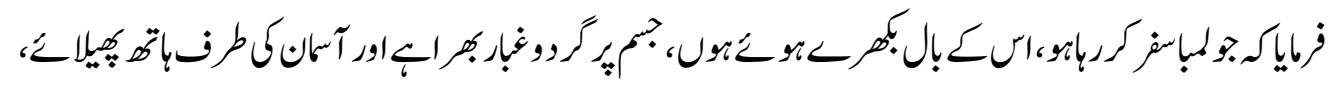

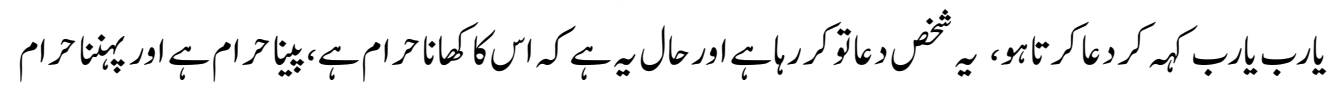

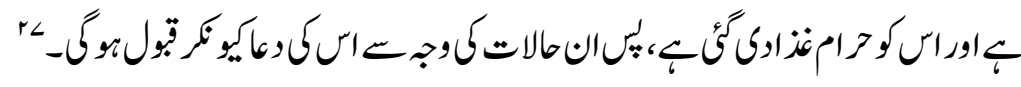

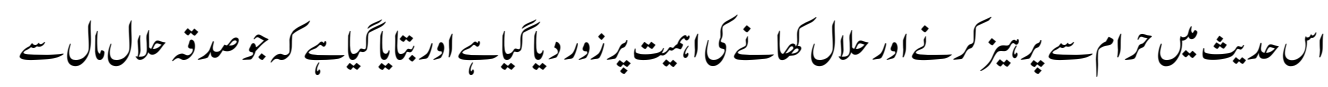

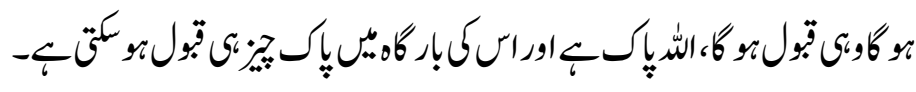

\section{حامروزك كميثرصور تئ}

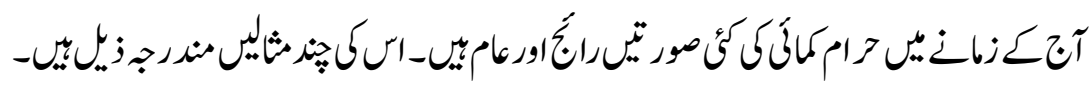

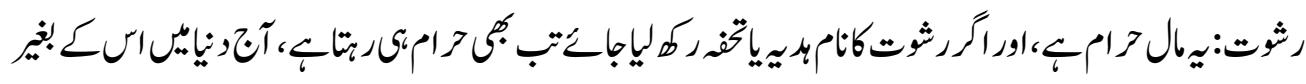

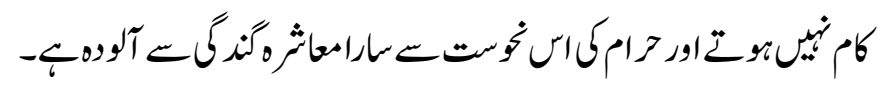




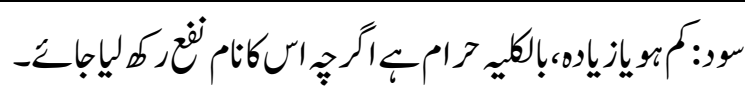

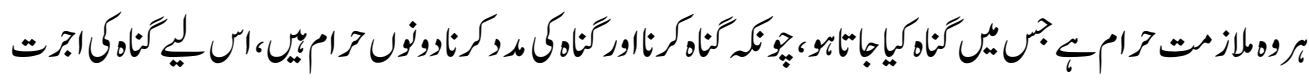

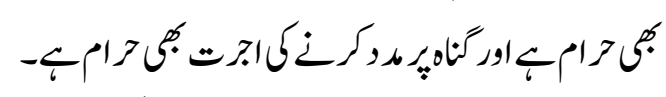

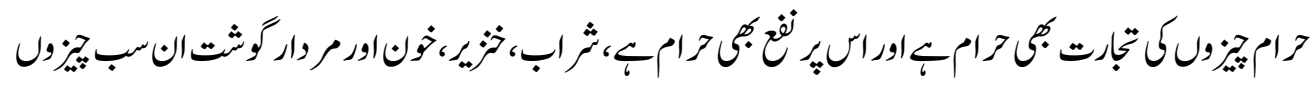

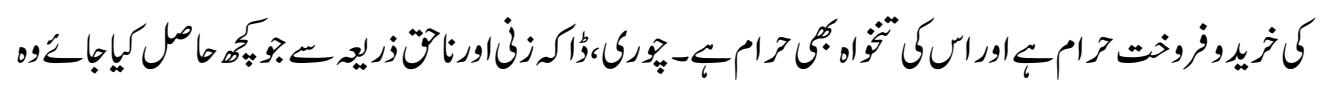

$$
\text { سب رام }
$$

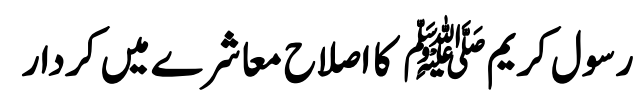

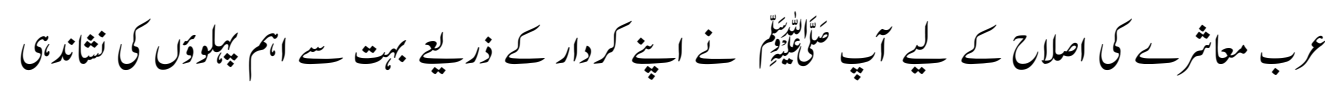

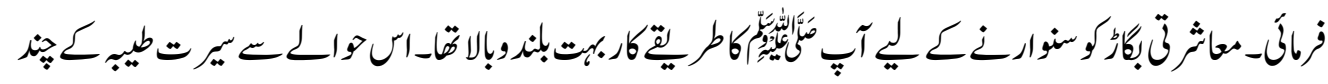

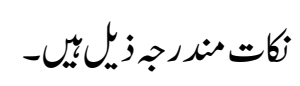

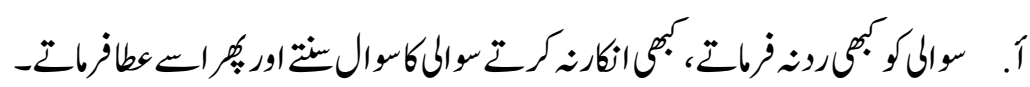

$$
\text { ب. كمكاباتن }
$$

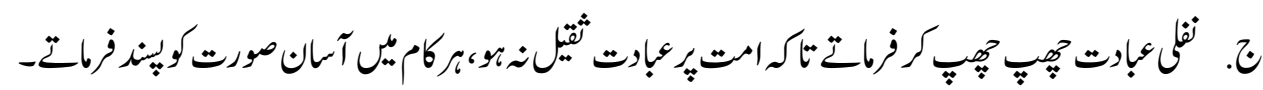

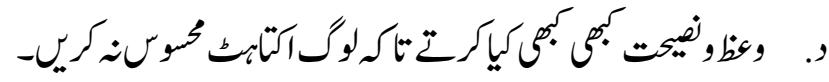

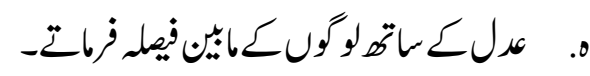

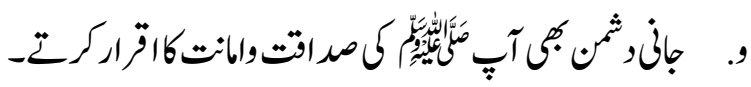

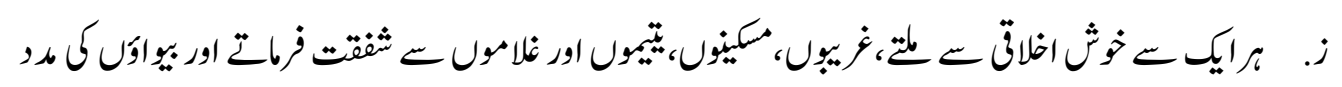

-

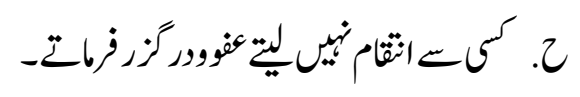

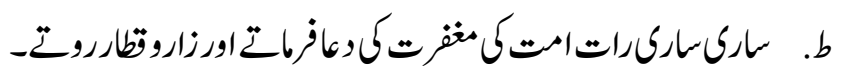




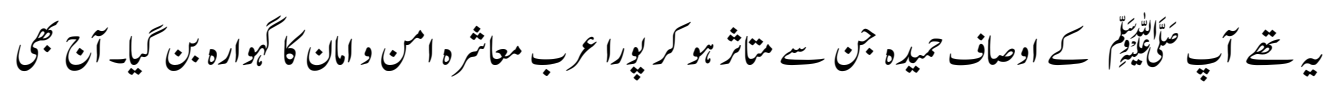

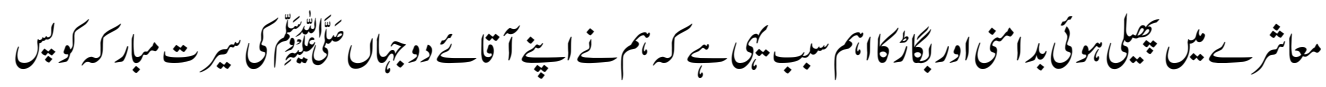

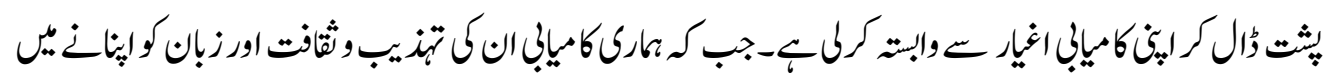

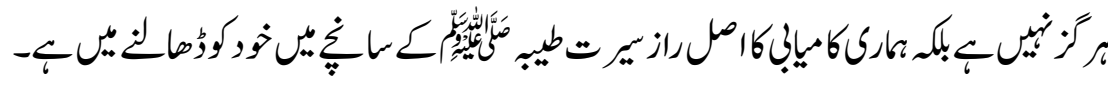

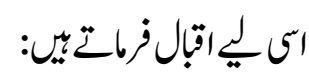

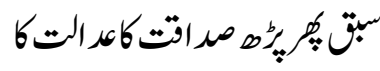

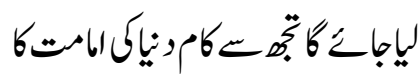

\begin{abstract}
مامدكام

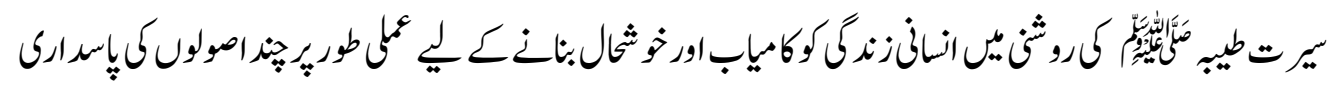

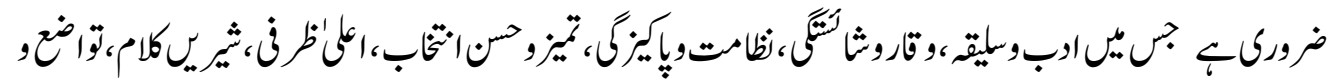

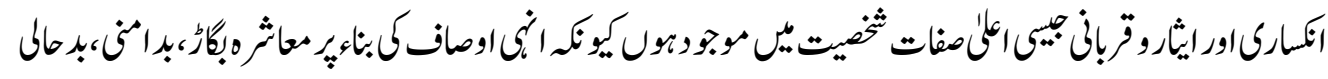

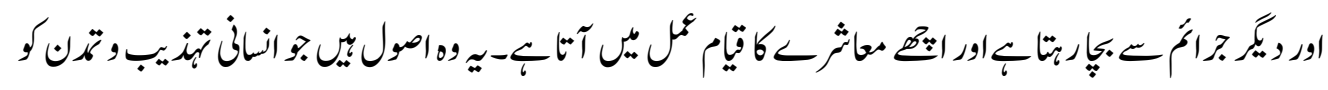

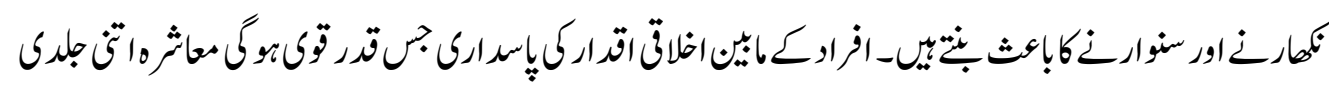

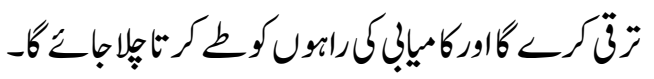

$$
\begin{aligned}
& \text { والم جإِ }
\end{aligned}
$$

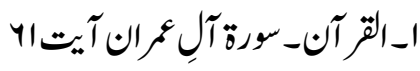

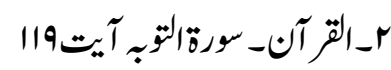

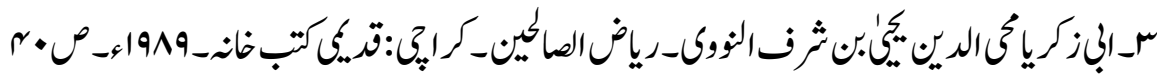

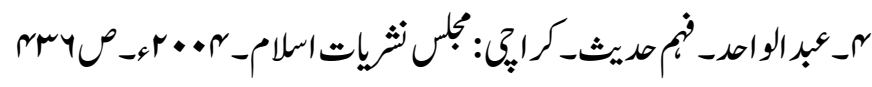




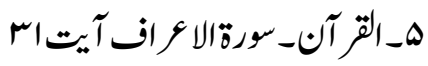

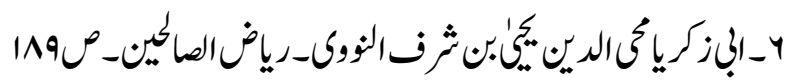

$$
\begin{aligned}
& \text { كــ اليضاً }
\end{aligned}
$$

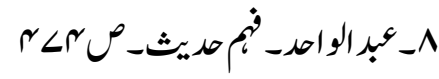

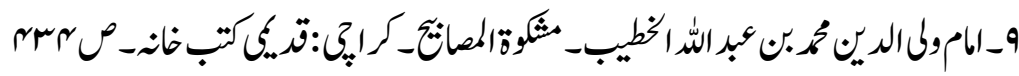

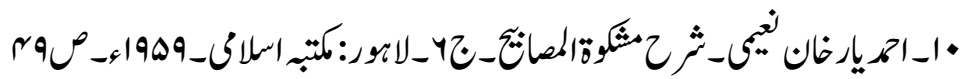

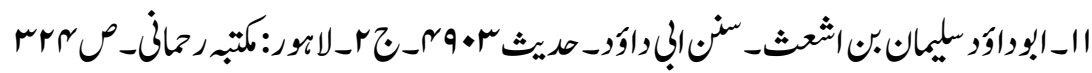

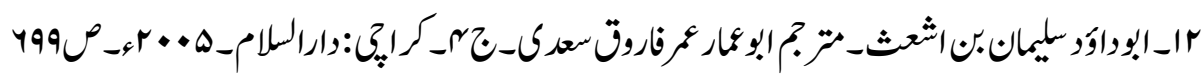

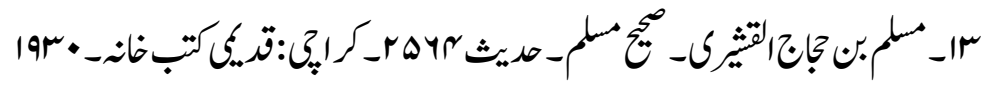

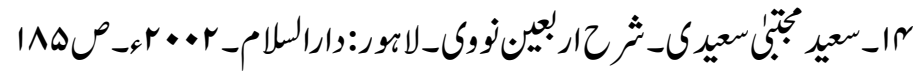

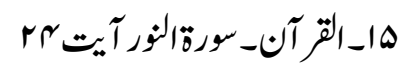

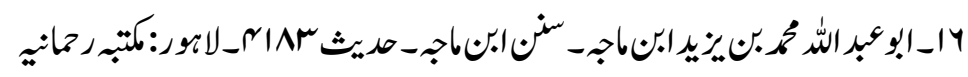

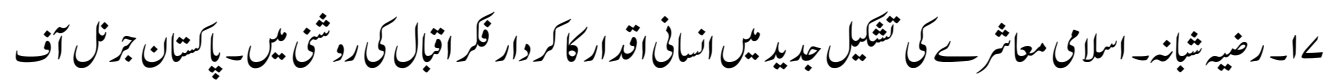

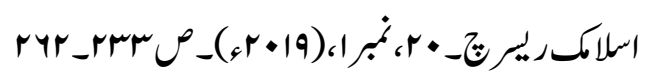

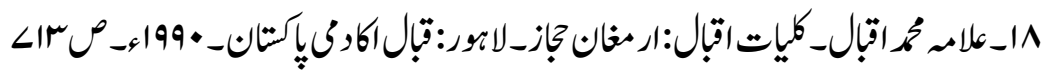

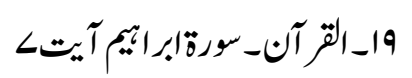

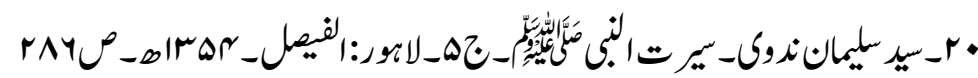

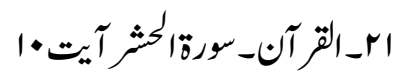

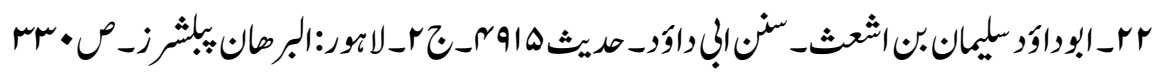

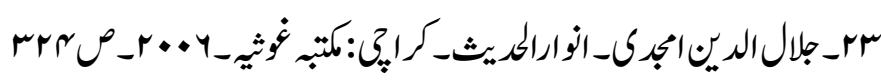

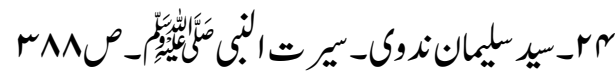

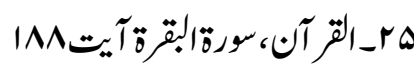




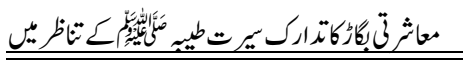

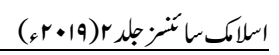
4r

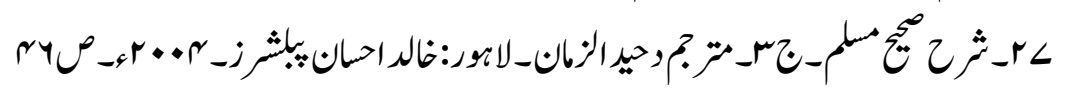

